\title{
USING WEB-BASED (RE)SOURCES IN TEACHING ACADEMIC-LEVEL ENGLISH
}

\author{
Emir Muhić, Dejan Milinović \\ University of Banja Luka, BIH
}

\begin{abstract}
:
Multimodality in the domain of teaching English at university level stands as an incontrovertible given. Novel Internet-facilitated methods emerge imperceptibly, thus incessantly occasioning conducive milieux for organic and topically pertinent mechanisms of language teaching.

This paper aims to underscore a skein of relevant content-abundant web-based resources successfully integrated into the curricular scope of advanced-level Contemporary English Language courses taught at the University of Banja Luka.

Conceptual categories from the purview of Internet linguistics will serve as the linchpin of the research tenor corroborating the notion that the creative process and its deliverables are cognitively enhanced by dint of real-life textual input easily accessible through the Internet. For the purposes of this small-scale survey samples from various dedicated online corpora and websites with online exercises such as the online Corpus of Contemporary American English, Breaking News English, Howjsay (an online dictionary of English pronunciation) will be used and conceptually parsed.
\end{abstract}

\author{
Key words: \\ Internet, \\ resources, \\ English, \\ linguistics, \\ teaching.
}

\section{THEORETICAL CONSIDERATIONS}

The early seventies of the last century saw the advent of a nouvelle-vague linguistic framework concurrent with the emergence of the overarching cognitivist and later constructionist approach to science. It primarily stemmed from rancorous dissatisfaction and disillusionment with meaning-devoid, formalistically and structuarally-geared frameworks and methodologies. With conceptually predicated systems, semanticity captured a long-denied echelon and became the lynchpin of empirical and descriptive treatises. The centrality of meaning, however, eclipsed the importance of the acquisition instantiation of the speaker's encyclopedic schematicity of linguistic capacity. This level of philological analysis is still largely circumscribed to the field of SLA enterprise (2nd Language Acquisition, Krashen, 1981). One of the lodestones of the paper is the ineluctable notion concerning the new expedients of knowledge transfer facilitated by dint of web-based platforms of instruction

An attempt will be made to merge the nascent theoretical insights into the endeavor of teaching English as a foreign language targeted at non-native audiences. This paper assumes a critical and question-provoking stance in an attempt to highlight selected flashpoints in EFL. Adequate weight is appended to the teaching-learning interface as delineated in this domain of scientific thought. The ultimate aim is the explication of an efficient medium of instruction applicable at university level.

\section{THE ARCANUM OF LANGUAGE}

The allure of language enshrines an ever-captivating mystery fathomed merely by the select few. It is doubtless an interminable fount of intellectual enterprise and perpetual academic exertion as well as a source of relentless and time-honored contention of utterly inconsiderable merit. This is by no means to aver that language is not to be credited with due attention, but, it does however venture a dauntless feat of playing hardball with prevalent points of contention meticulously stoked so as to keep the buzz going. The system of natural language grammar is imprinted onto the brain and the assumption is that if a child is to develop naturally and without excessive hindrances, the Universal Grammar within will indubitably emerge and formulate a necessary framework for successful communication. Chomsky is exceptionally keen on deep-surface structure correlations. This does sound 
convincing, but again, a multitude of exceptions closed ranks against this approach making it vulnerable and easily falsifiable. On the other hand, anti-Chomskyans claim that one of the reasons the theory is flawed is its relative resilience to falsifiability rendering itself too general and consequently detached. Another argument playing into the anti-Chomskyan hands is a complete disregard for meaning as a relevant and, perhaps, pivotal role of language. What good is a theory that takes no account of the one thing that underpins the whole idea of communication? This has been a long-standing intramural dispute not likely to be settled any time soon. The chronicles of the Grand Ivory Tower will inexorably immure Noam Chomsky into the very nave of its structure for excogitating a structure so transformative and yet timeless. The following borderline lamentation attests to this claim. Biologically speaking, we suspect that neural pathways depend on axons and dendrites. These synaptic couplings and intersections establish memory routes and storage activation. When the immensity of neurons, synapses, impulses and other cerebral constituents come together, they spark out a dazzling array of synchronicity and unequalled precision. They produce us. The very fabric of our being. Who we are, what we think and ultimately do. At least, that is what we think happens. Neurolinguistics is yet to be pitted against some of the most daunting and yet simplest challenges. For instance, what happens when a non-native speaker of English taps into their lexicon in search of the past participle of the verb "think" as compared to a native speaker who probably does not even 'think' about it longer that a mere second? Are different synapses activated and different impulses transmitted? These are just some of the questions we cannot hope to answer any time soon. We can only assume without even understanding how we perform the process of assuming in the first place. It would of course be unfair to say that bold and groundbreaking strides have not been made. Cognitive grammarians and theorist have made invaluable inroads into the illumination the meaning generation processes from a completely unique and impressively compelling perspective. Nonetheless, it would be naively callow to labor under the misapprehension of cognizance. No matter how heterogeneous and dissimilar languages seem at first blush, they ultimately demonstrate an uncanny resemblance suggesting there is a unifying common thread epitomized by the idea of a protolanguage, the forebear of all languages. Historical linguists would say that this is a virtually incontrovertible fact, however, a pinch of salt never goes amiss. Whatever approach we subscribe to, one thing remains certain. It is mysterious and exciting. And, many methodologists will agree, it is not learnt by instruction. If this is true, and if learning truly does not translate into acquisition, then, how do teachers, professors, instructors and foreign language school overlords keep their respective sinecures? The answer is as rare as a figurative Mesozoic bird. However, this remarkably rare phenomenon metaphorically epitomized in the aforementioned symbolic token might perhaps be found in the following practically-geared modes of utilizing web-based resources.

\section{THEORY IN USE}

The sections that follow will shed partial light on how ample and readily available Internet-facilitated resources are routinely put to practical use in teaching the English language, as well as Anglo-American literature and culture to students at the University of Banja Luka English Language and Literature Department.

\section{Background information}

The curriculum of the studies at our department revolves around three main complementary and more or less intertwined components - language, literature and culture, each with their distinctive approaches and aims, but working towards the common goal of producing competent English teachers, and to a lesser extent, translators and interpreters.

Although the language component comprises linguistic subjects, such as Syntax and Phonology, and methodology subjects, since we are working in an EFL environment, i.e. the students at our department are predominantly and expectedly non-native speakers, a key part of the language component (and incidentally of the entire studies curriculum) are the subjects of Contemporary English Language 1-8 (CELs), which are designed primarily to build and develop the students' language skills, in great part through translation exercises.

The linguistic subjects at the department can be seen in a way as supporting subjects for CELs, in the sense that they provide students with insight into the workings of the English language, thus hopefully giving them tools to improve their understanding and production of the language.

The following sections will explain in more detail how web-based materials have been used for the subjects of Contemporary English Language and Morphosyntax, as well as for EFL classes at other foreign language departments and faculties.

\section{Translation texts for Contemporary English Language}

With the aim of developing students' individual language skills (listening comprehension, writing, vocabulary), the subjects of Contemporary English Language comprise four integral components in separate classes, two of which are translation from English to Serbian and translation from Serbian to English.

When it comes to English to Serbian translation, the selection of the text plays a key role in the organization and outcome of any class, and it depends on which aims the class is supposed to meet. Registers are frequently rotated, in order to provide students with a variety of styles and genres, as well as to avoid saturation with one register. The most common registers used are literature (mainly noted fiction books), popular science and current newsbased texts in economy, world politics or social issues. The scarcity of print editions of these magazines and dailies in 
this region makes their online versions an excellent alternative with readily available first-rate texts and in some cases other teaching materials.

The sources are usually chosen from eminent magazines (National Geographic, Popular Science etc.) and news agencies (BBC, The Guardian, The Independent, The Economist, etc.), all with vast backgrounds of tradition and experience (for instance, The National Geographic magazine was launched in 1888, while The Guardian has been in press since as early as 1821), which means the authors of the texts are presumably native speakers who are highly qualified writers, producing well-structured and cohesive articles very suitable for use in the translation classroom.

\section{Examples for syntactic structures}

The subject of Morphosyntax explores the relations of words and structures within phrases and clauses hoping to make the students better understand how the English language functions.

There are several types of exercises that are provided during work with the students, some of which are taken from grammar workbooks, and some from other sources, such as the Internet. The most common exercise is where students are supposed to analyze example sentences and recognize and identify structures and categories taught and illustrated in the given lesson. The teacher is then tasked to find suitable example sentences in any corpora available.

Prior to the Internet era, the corpora were usually fiction books teachers had at their disposal. With the advancement of the Internet and the emergence of e-books, finding example sentences became easier because the search function enabled teachers to quickly find specific structures and integrate them into their lesson plans. The downside was that this kind of search required very specific and narrowly-targeted wording of the search phrases, meaning that for example a search for the verb "contemplated" would yield only instances of this exact verb form, and would exclude the infinitive and present participle, thus allowing for very little diversity in the results.

This constraint was first mitigated by websites such as Wordnik ${ }^{1}$, which itself used notable news websites as a corpus to draw results from and which allowed for some flexibility in the search results (i.e. the results included the whole paradigm of an entered word). The constraint was ultimately removed with the emergence of parsed online text databases, one of the most comprehensive of which are the Corpus of Contemporary American English (COCA) and British National Corpus (BYU-BNC), developed by Mark Davies from Brigham Young University in Provo, Utah, USA, which allow you to "search for exact words or phrases, wildcards, lemmas, part of speech, or any combinations of these" and "surrounding words (collocates) within a ten-word window (e.g. all nouns somewhere near faint, all adjectives near woman, or all verbs near feelings)." 2 This allows the teacher to find

1 Wordnik, www.wordnik.com

2 http://corpus.byu.edu/ many sequences which are composed of different words, but which fit a desired grammatical pattern, while making sure that they originate from relevant sources and are the product of live language. COCA and BYU-BNC further offer their data offline in the form of word frequency lists, collocate lists and n-grams, which can be useful in word frequency analysis etc.

\section{EFL for non-English majors}

English language taught at other foreign language departments and other faculties is usually at the intermediate level, since the groups are mixed between students who have learned very little English (if any). Those who have learned some English and those who are almost proficient, while the latter are a small minority.

These subjects are sometimes taught by dint of coursebooks by renowned publishers such as Cambridge University Press, Oxford University Press, MacMillan, Longman and others, but there happen to be subjects and classes where such books would not be viable, either due to availability factors, or they are not suitable to the size or profile of the group (the subject matter may be too easy for some students, and at the same time too difficult for others in the same group), or for some other unforeseeable reason.

Irrespective of the aforementioned, there are classes which require a different approach on the part of the teacher, and this is where online sources come in handy. For example, Breakingnewsenglish ${ }^{3}$ provides lessons and lesson plans that can be adapted for different-level learners. For a specific class, it provides a text, normally an adapted version of a report on some current affairs, and then provides numerous solutions for both pre-reading and post-reading activities. It offers several types of exercises for each of the four main language skills that are being targeted (speaking, listening, reading and writing) ranked by difficulty, so that in a mixed class the teacher can use the same lesson and assign similar but adjusted tasks to students of different levels. For example, a dictation exercise can be a full dictation for lower-level students, and a gap-fill dictation for higher-level students. Such exercises can be devised by the teachers themselves, but the availability of ready-made material online facilitates their work and enables them to focus their time and energy on other tasks.

Other sources, such as The Guardian's Learning English page ${ }^{4}$ offers "special news-based materials to support learners and teachers of English" with monthly "topical news articles" extended into photocopiable classroom worksheets, with pre-reading and post-reading activities and exercises, ranging from lower-intermediate to advanced level.

\section{Other subjects}

Teaching English phonetics and phonology to English majors in an EFL environment has two main goals - that

3 Breakingnewsenglish, www.breakingnewsenglish.com

4 The Guardian, http://www.theguardian.com/education/series/ classroom-materials 
of providing the future English teachers with theoretical and practical background for their work, and that of actually improving their pronunciation and speaking skills in the present. Today, the Internet provides a myriad of tools both for the classroom and students' autonomous learning, for example pronunciation resources such as Pronuncian $^{5}$, Sounds of English ${ }^{6}$, eslflow ${ }^{7}$, and many others.

Ready-made lesson plans, class ideas and instructional videos from websites such as TeacherTube $e^{8}$ and even YouTube $e^{9}$ can be an invaluable asset in teaching the subjects of Methodology of the English language.

When it comes to teaching subjects with cultural-oriented syllabi, the teacher is just a few clicks away from comprehensive historical material, such as the British History website ${ }^{10}$, to brief humoristic overviews such as The Open University's History of English in Ten Minutes ${ }^{11}$.

With the Internet, literature classes can be expanded from the text-based approach with websites such as poets. $\operatorname{org}^{12}$ which contain a plethora of poetry and information on the poets, to a multimedia classroom with videos of poets reciting their own or others writers' poems or critics giving analyses of works from the class curriculum, which can easily be discovered on the likes of YouTube or TeacherTube.

One can even easily find whole courses on specific subjects, such as the "Introduction to Theory of Literature"13 course at Yale University's Open Yale online program, with lesson videos, materials etc., parts of which can be integrated into a different literature class.

Going even further, the Internet provides myriad resources for autonomous learning through fully online courses. There are many websites offering free, fully online real-time courses, such as coursera.org ${ }^{14}$ or openculture. $\mathrm{com}^{15}$, with more and more prominent universities (Stanford University ${ }^{16}, \mathrm{MIT}^{17}$ ) opening up their gates to the Internet, which can provide students a means of further improving their skills in any desired direction.

\section{CONCLUSION}

Having analyzed this specifically targeted repository of web-based resources, a definitive conclusion can be drawn that instruction as well as acquisition of the English language and Anglo-American literature and culture have been greatly aided and improved by the advent of new technologies, making the whole process easier for the teacher. On the other hand, learning outcomes for stu-

5 Pronuncian, http://www.pronuncian.com/

6 Sounds of English, http://www.soundsofenglish.org/activities/index.htm

7 eslflow, www.eslflow.com/pronunciationlessonplans.html

8 TeacherTube, www.teachertube.com

9 YouTube, www.youtube.com

10 www.british-history.ac.uk

11 The Open University, http://www.open.edu/openlearn/history-thearts/culture/english-language/the-history-english-ten-minutes

12 poets.org, www.poets.org

13 Fry, Paul H., Introduction to Theory of Literature http://oyc.yale.edu/ english/engl-300\#sessions

14 Coursera, www.coursera.org

15 Open Culture, http://www.openculture.com/freeonlinecourses

16 Stanford University, http://online.stanford.edu/courses

17 Massachusetts Institute of Technology, http://ocw.mit.edu/index.htm dents are more easily attained when the subject matter is presented in a manner more entertaining and engaging, having in mind the simultaneous growth of both students and the new technologies.

This is merely an initial step into this enormous realm of possibilities, one which should lead to further, more significant strides in the field of language instruction at large via web-based resources, some of which have been cited in this paper.

By means of surveys and questionnaires to be conducted in class, further findings are to be derived as to the effectiveness of these new Internet-based methodologies. This is a natural next phase of this research. It is to be undertaken at a later stage with a view to yielding a specific case study and consequent extensive theoretical elaboration of the matter tackled in this small-scale prefatory paper serving as a stepping stone to further research.

\section{REFERENCES}

[1] Wordnik, www.wordnik.com

[2] http://corpus.byu.edu/

[3] Breakingnewsenglish, www.breakingnewsenglish.com

[4] The Guardian, http://www.theguardian.com/education/ series/classroom-materials

[5] Pronuncian, http://www.pronuncian.com/

[6] Sounds of English, http://www.soundsofenglish.org/activities/index.htm

[7] eslflow, www.eslflow.com/pronunciationlessonplans.html

[8] TeacherTube, www.teachertube.com

[9] Bybee, Joan L. "A View of Phonology from a Cognitive and Functional Perspective." Cognitive Linguistics 5, no. 4 (1994): 285-305.

[10] Ellis, Rod. Understanding Second Language Acquisition Oxford, England: Oxford U Press, 1986.

[11] Kristiansen, Gitte. "Towards a Usage-Based Cognitive Phonology." International Journal of English Studies 6, no. 2 (2006): 107-140.

[12] Lynn, Suzanne and Wayne ONeil. Linguistic Theory in Second Language Acquisition Dordrecht, The Netherlands: Kluwer Academic Publishers, 1988.

[13] Nathan, Geoffrey S. Phonology: A Cognitive Grammar Introduction x+171pp, Amsterdam: John Benjamins, 2008.

[14] Nathan, Geoffrey S. "Steps Towards a Cognitive Phonology." 1996.

[15] Pfaff, Carol Wollman. First and Second Language Acquisition Processes Cambridge, MA: Newbury House Publishers, 1987.

[16] Rosen, Russel S. "Beginning L2 Production Errors in ASL Lexical Phonology: A Cognitive Phonology Model.” Sign Language \& Linguistics 7, no. 1 (2004): 31-61.

[17] Valimaa-Blum, Riitta. "The Phoneme in Cognitive Phonology: Episodic Memories of both Meaningful and Meaningless Units?" CogniTextes: Revue De lAssociation Francaise De Linguistique Cognitive 2, (2009).

[18] Fry, Paul H. "Introduction to Theory of Literature". Open Yale courses. http://oyc.yale.edu/english/engl300\#sessions

[19] poets.org, www.poets.org

[20] Coursera, www.coursera.org

[21] Open Culture, http://www.openculture.com/freeonlinecourses

[22] Stanford University, http://online.stanford.edu/courses

[23] Massachusetts Institute of Technology, http://ocw.mit. edu/index.htm 